Janssen, Lilly, Merck, Novartis, Pfizer, Regeneron, Samsung, Sanofi and UCB, R. Ganguly Shareholder of: GlaxoSmithKline, Employee of: GlaxoSmithKline, N. Li Shareholder of: Janssen Research \& Development, LLC, Employee of: Janssen Research \& Development, LLC, K. McQuarrie Shareholder of: Janssen Research \& Development, LLC, Employee of: Janssen Research \& Development, LLC DOI: 10.1136/annrheumdis-2017-eular.3904

\section{SAT0183 CLINICAL REMISSION IN SUBJECTS WITH RHEUMATOID ARTHRITIS TREATED WITH SUBCUTANEOUS TOCILIZUMAB AS MONOTHERAPY OR IN COMBINATION WITH METHOTREXATE OR OTHER SYNTHETIC DMARDS: A REAL- WORLD CLINICAL TRIAL (TOSPACE)}

R. Sanmarti ${ }^{1}$, E. Martín Mola ${ }^{2}$, J.E. Fonseca ${ }^{3}$, D.J. Veale ${ }^{4}$, A. Escudero ${ }^{5}$, C. González ${ }^{6}$ on behalf of ToSpace Study group. ${ }^{1}$ Hospital Clinic, Barcelona; ${ }^{2}$ Hospital la Paz, Madrid, Spain: ${ }^{3}$ Hospital de Santa Maria, Lisboa, Portugal;

${ }^{4}$ St. Vincent's University Hospital, Dublin, Ireland; ${ }^{5}$ Hospital Reina Sofía,

Córdoba; ${ }^{6}$ Hospital Gregorio Marañón, Madrid, Spain

Background: Subcutaneous tocilizumab (TCZ-SC) has demonstrated noninferiority to TCZ-IV and superiority to placebo

Objectives: The primary objective of this study was to assess the 24-week efficacy and safety of subcutaneous (SC) tocilizumab (TCZ) $162 \mathrm{mg}$ weekly (qw) as monotherapy or in combination with methotrexate (MTX) or other synthetic (s) DMARDs in patients with active rheumatoid arthritis (RA) in the real world setting Methods: This multinational (Spain, Ireland, Portugal), multicenter, phase Illb study. Subjects $\geq 18$ years of age with active RA (DAS 28-ESR >3.2) who have had inadequate response or intolerance to sDMARDs or to a first anti-TNF drug. The study comprised a phase 1 with open-label design in which patients received TCZ-SC $162 \mathrm{mg} \mathrm{qw} \mathrm{(+/-} \mathrm{oral/SC} \mathrm{MTX} \mathrm{or} \mathrm{other} \mathrm{sDMARDs)} \mathrm{for} \mathrm{24-weeks} \mathrm{and}$ the main outcome was the percentage of patients achieving sustained clinical remission (DAS 28-ESR <2.6) at Week 20 and Week 24 (primary outcome of the study); and a phase 2 where patients achieving sustained clinical remission during the phase 1 were randomized to receive TCZ-SC $162 \mathrm{mg}$ qw or TCZ-SC $162 \mathrm{mg} \mathrm{q} 2 \mathrm{w}$ (+/- oral/SC MTX or other sDMARDs) for an additional 24 weeks; the main outcome of the phase 2 was the percentage of patients who maintained the remission at week 48 (i.e. DAS 28-ESR<2.6)

Results: 401 patients were included in the phase 1,74 patients received TCZ-SC monotherapy and 327 patients received TCZ-SC in combination with oral/SC MTX or other SDMARDs. Sustained clinical remission rates were comparable between the mono- and combination-therapy groups at 24 week $(48.4 \%$ vs. $52.9 \%, p=0.523)$. Of the 179 patients who achieved sustained clinical remission during the phase 1,89 were randomly assigned to receive TCZ-SC $162 \mathrm{mg}$ qw and 90 to receive TCZ-SC $162 \mathrm{mg}$ q2w. At the end of phase 2, the percentage of patients who maintained the remission at week 48 was $91.5 \%$ with TCZ-SC qw and $73.9 \%$ with TCZ-SC q2w ( $p=0.002)$. Main efficacy outcomes for both phases of the study are presented in the table. Rates of serious adverse events (AEs) and rates of AEs leading to drug discontinuation were similar in patients treated with mono or combination therapy, and in patients treated with TCZ-SC qw or TCZ-SC q2w.

\begin{tabular}{lccc}
\hline Phase 1 - Outcome & $\begin{array}{c}\text { TCZ-SC monotherapy } \\
\mathrm{N}=74\end{array}$ & $\begin{array}{c}\text { TCZ-SC Combination } \\
\mathrm{N}=327\end{array}$ & p-value \\
\hline Sustained clinical remission, \% & 48.4 & 52.9 & 0.523 \\
ACR20, \% & 79.7 & 83.3 & 0.495 \\
ACR50, \% & 59.4 & 58.7 & 0.923 \\
ACR70, \% & 40.6 & 37.7 & 0.666 \\
ACR90, \% & 23.4 & 16.7 & 0.207 \\
HAQ-DI (baseline/24 weeks), mean & $1.49 / 0.85$ & $1.36 / 0.82$ & $\mathrm{NS}$ \\
\hline Phase 2 - Outcome & TCZ-SC 162 mg qw & TCZ-SC 162 mg q2w & \\
& $\mathrm{N}=89$ & $\mathrm{~N}=90$ & $\mathrm{p}$-value \\
\hline Clinical remission, \% & 91.5 & 73.9 & 0.002 \\
ACR20, \% & 96.4 & 88.8 & 0.056 \\
ACR50, \% & 88.1 & 79.8 & 0.766 \\
ACR70, \% & 71.4 & 65.2 & 0.377 \\
ACR90, \% & 45.2 & 32.6 & 0.088 \\
Mean change in DAS28 & -0.02 & 0.35 & 0.037 \\
\hline
\end{tabular}

Conclusions: In the real world setting, treatment with TCZ-SC 162 mg weekly in patients with active RA is associated with rate of sustained clinical remission of approximately $50 \%$ regardless it is administered as monotherapy or in combination with a sDMARD. The proportion of patients who remained in clinical remission at week 48 was significantly higher with TCZ-SC qw than with TCZ-SC q2w. The safety profile of TCZ-SC was consistent with previous studies of TCZ-SC and TCZ-IV

Disclosure of Interest: R. Sanmarti Grant/research support from: Roche, E. Martín Mola Grant/research support from: Roche, J. Fonseca Grant/research support from: Roche, D. Veale Grant/research support from: Roche, A. Escudero Grant/research support from: Roche, C. González Grant/research support from: Roche

DOI: 10.1136/annrheumdis-2017-eular.4951

\section{SAT0184 THERAPEUTIC DRUG MONITORING ON RHEUMATOID ARTHRITIS PATIENTS WITH REDUCED DOSES OF INTRAVENOUS TOCILIZUMAB}

V. Ruiz-Esquide ${ }^{1}$, C. Bastida ${ }^{2}$, M. Pascal ${ }^{2}$, J. Yagüe ${ }^{3}$, D. Soy ${ }^{2}$, R. Sanmartí ${ }^{1}$ ${ }^{1}$ Rheumatology; ${ }^{2}$ Pharmacy; ${ }^{3}$ Immunology, Hospital Clínic de Barcelona, Barcelona, Spain

Background: Tocilizumab (TCZ) is an effective treatment for rheumatoid arthritis (RA). Literature suggests there is great variability in intravenous (iv) TCZ serum concentrations among individuals. Moreover, optimal drug dosage does not seem to be clear since Regulatory Agencies (FDA and EMA) approved the drug with a different initial posology. Empirical dose de-escalation strategies are being fostered in patients with disease remission.

Objectives: The purpose of the study was to examine TCZ serum concentrations at the different prescribed doses in RA. Secondary objectives were to evaluate the relationship between drug serum concentrations and laboratory parameters of disease activity.

Methods: Prospective, observational, single-center study conducted in a university tertiary hospital. Enrolled RA patients received iv TCZ at a dose range from 4 to $8 \mathrm{mg} / \mathrm{kg}$ every 28 days. Demographic characteristics and clinical laboratory data were obtained at study entry. Blood samples for drug concentration testing were collected from the third TCZ dose onwards, just before TZC infusion and, when possible, once a week until the next drug administration.

Results: 35 patients $(88.6 \%$ women, $80 \%$ Caucasian) were included. Mean age $\pm S D$ was $54.1 \pm 12.3$ and the median [range] of disease duration was 11.1 [2.9-48.5] years. Median treatment duration with iv TCZ was 36.5 [3-68] months. $54 \%$ of patients received the standard dose of $8 \mathrm{mg} / \mathrm{kg}$ whereas the rest received reduced doses $(23 \%$ were on $6 \mathrm{mg} / \mathrm{kg}$ and $23 \%$ on $4 \mathrm{mg} / \mathrm{kg}$ ) due to persistent remission/low disease activity. 20 patients $(57.1 \%)$ were being treated with low steroid dose and $24(68.6 \%)$ were on concomitant DMARD, mainly methotrexate. Regarding drug concentration testing, a total of 109 samples were obtained. 19 patients participated to multiple drug sampling between two drug administrations and in the 17 remaining patients, a pre-dose sample was drawn. Mean TCZ concentrations are displayed in table 1 and showed in figure 1. No significant differences were observed in median pre-dose TCZ concentration values $(54$ samples) between patients on 8 and $6 \mathrm{mg} / \mathrm{kg}$ whereas significant lower drug levels were observed in those taking $4 \mathrm{mg} / \mathrm{kg}$.

According to inflammatory parameters, mean C-reactive protein (CRP) concentration was significantly lower in those patients with trough TCZ concentrations $>1 \mu \mathrm{g} / \mathrm{mL}$ compared to those $<1 \mu \mathrm{g} / \mathrm{mL}(0.066 \mathrm{mg} / \mathrm{dL}$ vs $0.689 \mathrm{mg} / \mathrm{dL}$, respectively; $\mathrm{p}<0.001)$. This difference was not observed with calprotectin serum concentrations $(2.260 \mu \mathrm{g} / \mathrm{mL}$ vs $2.143 \mu \mathrm{g} / \mathrm{mL})$.

Table 1. Mean ( \pm sd) iv TCZ serum concentrations at different prescribed doses within time

\begin{tabular}{|c|c|c|c|}
\hline Time (days) & $\mathrm{TCZ} 8 \mathrm{mg} / \mathrm{kg}$ & $\mathrm{TCZ} 6 \mathrm{mg} / \mathrm{kg}$ & $\mathrm{TCZ} 4 \mathrm{mg} / \mathrm{kg}$ \\
\hline Pre-infusion (Ctrough) & $8.9 \pm 6.1$ & $5.7 \pm 9.1$ & $0.8 \pm 1.2$ \\
\hline T7 & $84.8 \pm 33.9$ & $48.8 \pm 18.6$ & $26.1 \pm 6.4$ \\
\hline T14 & $46.4 \pm 19.8$ & $31 \pm 11.4$ & $15.2 \pm 5.6$ \\
\hline T21 & $21.6 \pm 9.5$ & $19.7 \pm 10.5$ & $7.1 \pm 4.4$ \\
\hline T28 (Ctrough) & $10.6 \pm 7.3$ & $10.3 \pm 10.8$ & $1.3 \pm 2.3$ \\
\hline
\end{tabular}

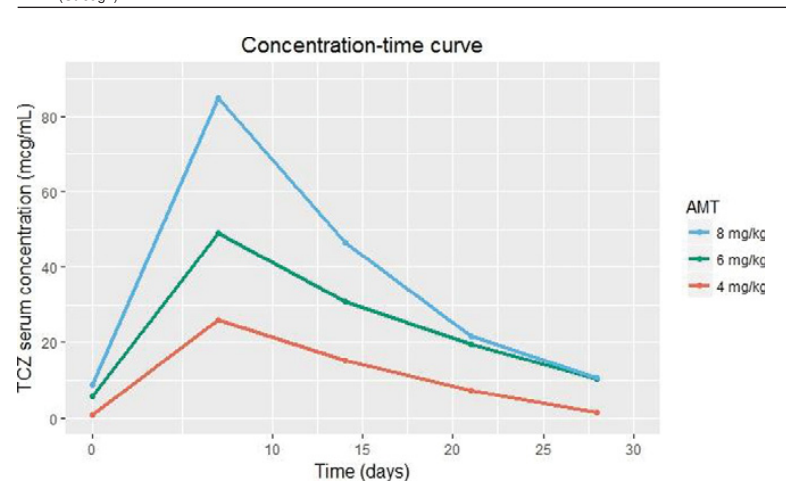

Figure 1. Mean iv TCZ serum concentrations at different prescribed doses (AMT) within time.

Conclusions: Trough TCZ serum concentrations do not differ between patients on an 8 and $6 \mathrm{mg} / \mathrm{kg}$ regimen. Therefore, according to the pharmacokinetics observed in our study, a maintenance dose of iv TCZ $6 \mathrm{mg} / \mathrm{kg}$ would be appropriate for most RA patients. Although CRP levels are significantly higher in patients with trough iv TCZ concentrations $<1 \mu \mathrm{g} / \mathrm{mL}$, serum calprotectin did not show the same tendency.

Disclosure of Interest: None declared

DOI: 10.1136/annrheumdis-2017-eular.4518 